\title{
New Facile Synthesis of Adamantyl Isothiocyanates
}

\author{
Vladimir Burmistrov \\ Dmitry Pitushkin \\ Gennady Butov*
}

Department of Chemistry, Technology and Equipment of Chemical Industry, Volzhsky Polytechnic Institute (Branch)

Volgograd State Technical University, 404121 Volzhsky,

Engels st., 42a, Russia

butov@volpi.ru

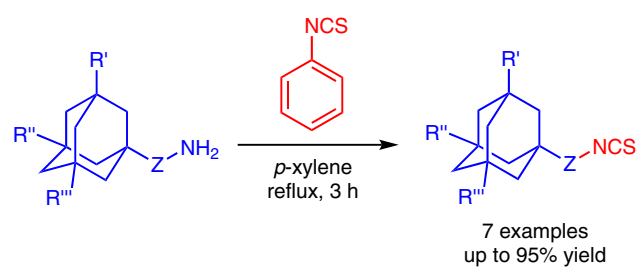

Received: 20.07 .2017

Accepted after revision: 29.08.2017

Published online: 15.09 .2017

DOI: 10.1055/s-0036-1588574; Art ID: so-2017-d0030-I

License terms: Cc)

Abstract A series of adamantyl isothiocyanates containing different substituents in the nodal positions of adamantane or spacers between the adamantane and isothiocyanate group have been synthesised by using the reaction of the corresponding adamantyl amines with phenyl isothiocyanate.

Key words adamantane, isothiocyanates, amines, thioureas, metathesis

Adamantyl isothiocyanates are promising precursors for the synthesis of various biologically active compounds. Thioureas formed from adamantyl isothiocyanates are promising as soluble epoxide hydrolase (sEH, E.C. 3.3.2.10) inhibitors, ${ }^{1}$ and as urokinase-type plasminogen activator (uPA, 3.4.21.73) inhibitors. ${ }^{2}$ Moreover, thioureas can be readily transformed ${ }^{3}$ into ureas, which find wide applications in medicinal chemistry. ${ }^{4}$

Traditional methods for the preparation of 1-adamantyl isothiocyanate require corrosive or toxic reagents, including the reactions of 1-aminoadamantane with $\mathrm{CS}_{2}$ and $\mathrm{NaOH},{ }^{5}$ 1-aminoadamantane with thiophosgene and $\mathrm{CaCO}_{3},{ }^{6}$ chloroadamantane with trimethylsilyl isothiocyanate and titanium(IV) chloride, ${ }^{7}$ along with bromoadamantane with KSCN. ${ }^{8}$ Modern methods involve the use of catalysts. ${ }^{9}$ However, there is still no simple and effective method for the preparation of 1-adamantyl isothiocyanate and its analogues.

Previously, we reported the synthesis of a library of adamantyl ureas from the reaction of either 1-adamantyl isocyanate or its homologues with various amines or 1-amino- adamantane or its homologues with isocyanates and diisocyanates. ${ }^{10}$ These reactions were carried out in the absence of base $\left(\mathrm{Et}_{3} \mathrm{~N}, \mathrm{DIPEA}\right)$. The reaction of 1-amino-3,5-dimethyladamantane 1 with phenyl isothiocyanate under similar conditions led to the formation of an unexpected mixture of products. ${ }^{11}$ Along with the expected thiourea 2, formation of isothiocyanate $\mathbf{3}$ also took place (Scheme 1).

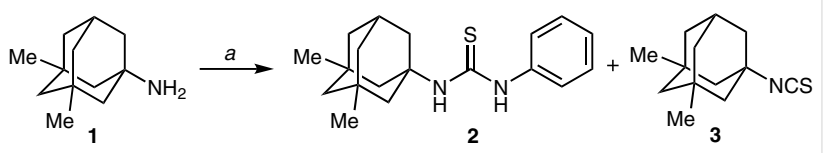

Scheme 1 Reaction in which the functional group metathesis was discovered. Reagents and conditions: (a) Ph-NCS (ratio 1:1 with 1), DMF, r.t., overnight, $12 \%$ (3).

Initially, the yield of 3 in this first reaction was $12 \%$. We speculated that the course of the reaction is driven by the basicity of the medium and by the structure of the reactants, and we decided to study this reaction with 1-adamantylamine $\mathbf{4}$ and defined conditions that reduced the thiourea yield. The reaction course was not affected by temperature; stirring in toluene at r.t. overnight gave a small amount of adamantyl isothiocyanate 5 but no 1-(adamantan-1-yl)-3-phenyl thiourea $\mathbf{6}$ was detected. In nonpolar hexanes, the formation of adamantyl isothiocyanate was not observed. In fact, thiourea $\mathbf{6}$ precipitated in quantitative yield seconds after addition of the reactants and before heating was initiated. The highest yield for adamantyl isothiocyanate 5 (47\%) was achieved at reflux for $3 \mathrm{~h}$ in $p$-xylene (Scheme 2). Furthermore, quantities of diphenyl thiourea and diadamantyl thiourea were detected in the reaction mixture. 


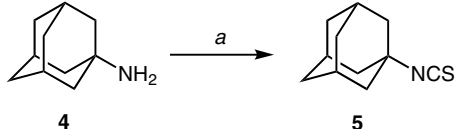

Scheme 2 Reagents and conditions: (a) Ph-NCS (ratio 1:1 with 4), p-xylene, reflux, $3 \mathrm{~h}, 47 \%$.

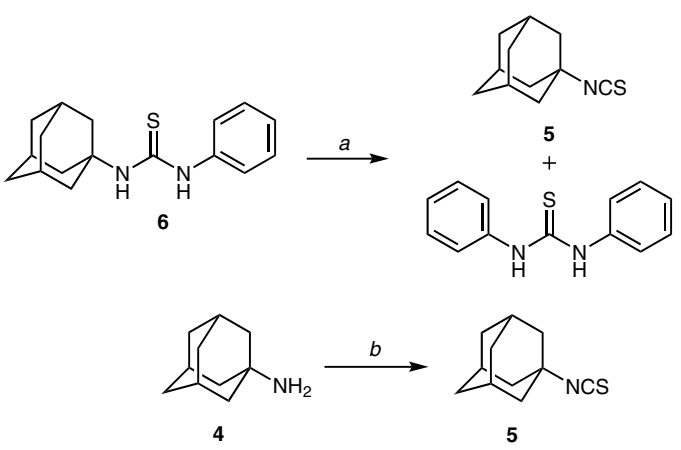

Scheme 3 Reagents and conditions: (a) Ph-NCS (ratio 1:1 with 6), p-xylene, reflux, 3 h, 95\%; (b) Ph-NCS (ratio 1:2 with 4), p-xylene, reflux, $3 \mathrm{~h}$, $95 \%$.

Initially, the proposed mechanism for the described reaction was based on the mechanism of urea formation described by Satchell and co-workers. ${ }^{12}$ Formation of urea goes through the three molecular transition state formed by amine, isocyanate and base. In some cases, another molecule of amine could act as a base. However, trimolecular mechanisms are usually only suitable when one of the reactants is added in excess. A metathesis reaction was earlier investigated between phenyl isothiocyanates and sterically hindered aromatic amines by Habib and Rieker. ${ }^{13}$ The authors stated that the reaction proceeds through the formation of the thiourea, followed by its thermal decomposition $\left(190{ }^{\circ} \mathrm{C}\right)$. Thus, we proposed that thiourea 6 could be an intermediate in this reaction. To confirm this assumption, 1(adamantan-1-yl)-3-phenyl thiourea 6 was synthesised according to a known method ${ }^{14}$ and then heated at reflux in toluene for 8 hours, but no traces of the corresponding adamantyl isothiocyanate 5 were detected. Most likely, $110{ }^{\circ} \mathrm{C}$ is not high enough to result in thermal decomposition of the thiourea. This was also the situation after $\mathbf{6}$ was treated under the same conditions in the presence of 1 equivalent of 1-adamantylamine 4. However, heating thiourea 6 at reflux in toluene with 1 equivalent of phenyl isothiocyanate led to the formation of adamantyl isothiocyanate $\mathbf{5}$ with 95\% yield (Scheme 3, b). Another product of this reaction was diphenyl thiourea. Furthermore, this means that phenyl isothiocyanate can furnish adamantyl isothiocyanates from nonsymmetric thioureas (Scheme 4). This new mechanism requires the thiourea formed in the first step to be soluble in a selected solvent in order to react with phenyl isothiocyanate; in hexanes, the formation of adamantyl isothiocyanate 5 was not observed because thiourea 6 precipi- tated from the solution. Thiourea is reported to have isothiourea tautomers. ${ }^{15}$ Moreover, the yield of adamantyl isothiocyanate cannot exceed 50\% when the reagents are added in a 1:1 ratio. The proposed mechanism also explains the difference in yields between various conditions. In basic medium (DMF), most of the phenyl isothiocyanate was rapidly consumed in the formation of thiourea $\mathbf{2}$, and only $12 \%$ of it managed to react with thiourea to give isothiocyanate 3 . In contrast, in nonbasic $p$-xylene, the formation of thiourea 2 was slowed and excess phenyl isothiocyanate could convert it into isothiocyanate 3 with $47 \%$ yield.

The next step was to determine the scope of this reaction. Firstly, aminoadamantanes containing two and three methyl substituents at the nodal positions, 1-amino-3,5dimethyladamantane and 1-amino-3,5,7-trimethyladamantane, respectively, were reacted with 2 equivalents of phenyl isothiocyanate to give the corresponding isothiocyanates $\mathbf{3}$ and $\mathbf{7}$ with $80 \%$ and 75\% yield (Table 1). Next, the influence of the distance between amino and adamantane groups was studied. For this purpose, aminoadamantanes with aliphatic spacers between the amino group and adamantane, 1-(aminomethyl)adamantane,1-(2-aminoethyl)adamantane and 1-(1-aminoethyl)adamantane were used. 2-Aminoadamantane used in the preparation of isothiocyanate 11 behaved like 1 -aminoadamantane. ${ }^{17}$

Table 1 Functional Group Metathesis Reaction between Adamantyl Amines and Phenyl Isothiocyanate

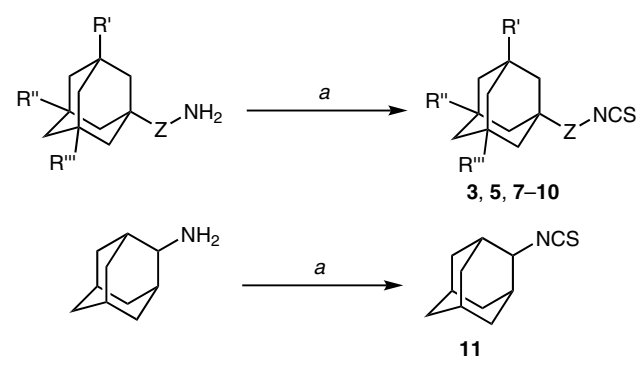

\begin{tabular}{lllllc}
\hline Entry & $\mathrm{R}^{\prime}$ & $\mathrm{R}^{\prime \prime}$ & $\mathrm{R}^{\prime \prime \prime}$ & $\mathrm{Z}$ & Yield (\%) \\
\hline 1 & $\mathrm{CH}_{3}$ & $\mathrm{CH}_{3}$ & $\mathrm{H}$ & no spacer & $\mathbf{3}, 80$ \\
2 & $\mathrm{H}$ & $\mathrm{H}$ & $\mathrm{H}$ & no spacer & $\mathbf{5}, 95$ \\
3 & $\mathrm{CH}_{3}$ & $\mathrm{CH}_{3}$ & $\mathrm{CH}_{3}$ & no spacer & $\mathbf{7 , 7 5}$ \\
4 & $\mathrm{H}$ & $\mathrm{H}$ & $\mathrm{H}$ & $\mathrm{CH}_{2}$ & $\mathbf{8 , 7 5}$ \\
5 & $\mathrm{H}$ & $\mathrm{H}$ & $\mathrm{H}$ & $\mathrm{CH}_{2} \mathrm{CH}_{2}$ & $\mathbf{9 , 7 8}$ \\
6 & $\mathrm{H}$ & $\mathrm{H}$ & $\mathrm{H}$ & $\mathrm{CH}\left(\mathrm{CH}_{3}\right)$ & $\mathbf{1 0 , 8 6}$ \\
7 & - & - & - & - & $\mathbf{1 1 , 9 2}$ \\
\hline
\end{tabular}

a Reagents and conditions: Ph-NCS (ratio 1:2 with adamantane starting material), $p$-xylene, reflux, $3 \mathrm{~h}$.

We also examined whether a similar reaction took place when the isothiocyanate was replaced by an isocyanate. Replacement of phenyl isothiocyanate with phenyl isocyanate led to the formation of the corresponding urea in quantita- 

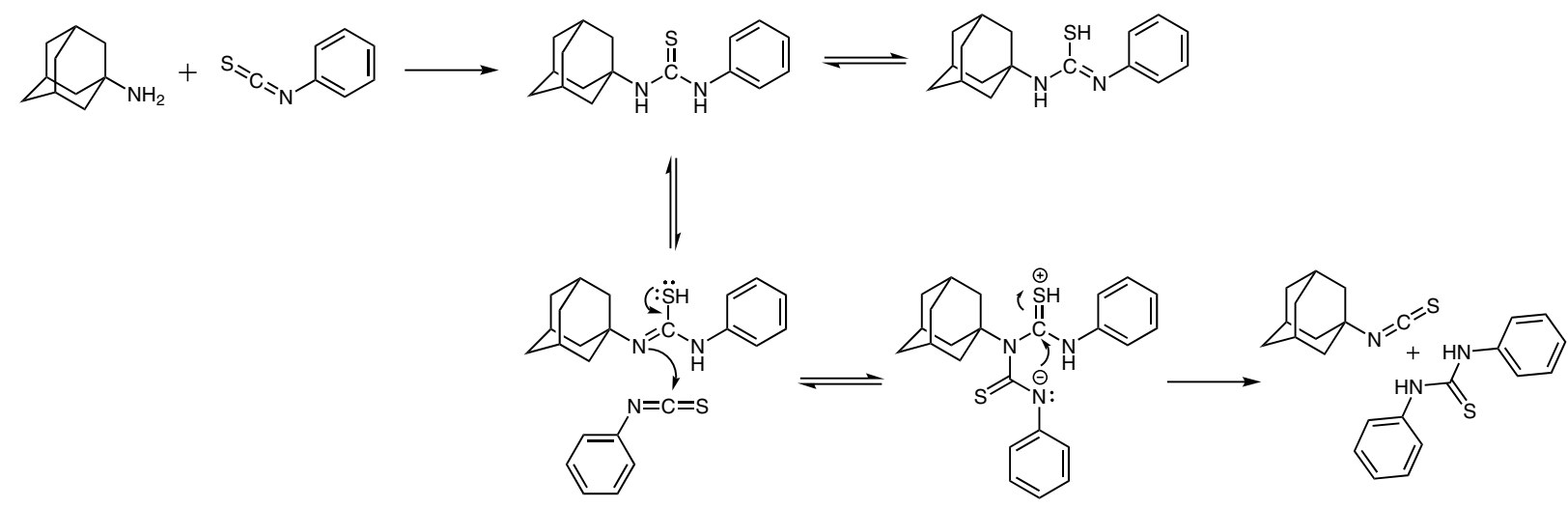

Scheme 4 Proposed mechanism of the functional group metathesis reaction

tive yield. Thiourea was the only product formed when the adamantyl amine was replaced with an aliphatic amine (ethyl, $i$-propyl, tert-butyl, hexadecyl or octadecyl amine). This probably happens due to the higher basicity and thus rapid interaction with phenyl isothiocyanate of aliphatic amines and impossibility of thermal decomposition of thioureas under the reported conditions. Consequently, when aliphatic diamines (1,2-ethanediamine, 1,3-propanediamine, 1,4-butanediamine and 1,6-hexanediamine) were reacted with phenyl isothiocyanate under the same conditions, ${ }^{16}$ trace amounts of imidazolidine-2-thione, tetrahydropyrimidine-2(1H)-thione and 1,3-diazepane-2-thione, respectively, were obtained. These are the cyclisation products of 2-isothiocyanatoethan-1-amine, 3-isothiocyanatopropan-1-amine and 4-isothiocyanatobutan-1-amine. In the case of 1,6-hexanediamine, the corresponding thione was not detected.

In conclusion, a promising new method for the synthesis of isothiocyanates bearing the adamantane moiety was developed. The described method gives high yields under mild conditions without requiring additional catalysts.

\section{Funding Information}

This work was supported by the Russian Fund for Basic Research (grant number 16-33-00172) and by the Ministry of Education and Science of the Russian Federation (base part of state assignment for 2017-2019; project no. 4.7491.2017/BCh).

\section{Acknowledgment}

The authors thank Dr. Sung Hee Hwang for support in discussions of the results.

\section{Supporting Information}

Supporting information for this article is available online at https://doi.org/10.1055/s-0036-1588574.

\section{References and Notes}

(1) Butov, G. M.; Burmistrov, V. V.; Danilov, D. V.; Pitushkin, D. A.; Morisseau, C.; Hammock, B. D. Russ. Chem. Bull. 2015, 64, 1569.

(2) Venkatraj, M.; Messagie, J.; Joossens, J.; Lambeir, A. M.; Haemers, A.; Van der Veken, P.; Augustyns, K. Bioorg. Med. Chem. 2012, 20, 1557.

(3) Lakouraj, M. M.; Ghodrati, K. Monatsh. Chem. 2008, 139, 549.

(4) (a) Kodani, S. D.; Hammock, B. D. Drug Metab. Dispos. 2015, 43, 788. (b) Lee, K. S. S.; Liu, J.-Y.; Wagner, K. M.; Pakhomova, S.; Dong, H.; Morisseau, C.; Fu, S. H.; Yang, J.; Wang, P.; Ulu, A.; Mate, C. A.; Nguyen, L. V.; Hwang, S. H.; Edin, M. L.; Mara, A. A.; Wulff, H.; Newcomer, M. E.; Zeldin, D. C.; Hammock, B. D. J. Med. Chem. 2015, 57, 7016.

(5) Takeda, K.; Tsuboyama, K.; Takeura, M. Chem. Pharm. Bull. 1989, 37, 2334.

(6) Nam, K. D.; Han, M.; Yoon, J.; Kim, E.; Cho, S.; Hahn, H. Bull. Korean Chem. Soc. 2013, 34, 271.

(7) Sasaki, T.; Nakanishi, A.; Ohno, M.J. Org. Chem. 1981, 46, 5445.

(8) Stetter, J.; Wulff, D. Chem. Ber. 1962, 95, 2302.

(9) Scattolin, T.; Klein, A.; Schoenebeck, F. Org. Lett. 2017, 19, 1831.

(10) (a) Burmistrov, V.; Morisseau, C.; Lee, K. S. S.; Shihadih, D. S.; Harris, T. R.; Butov, G. M.; Hammock, B. D. Bioorg. Med. Chem. Lett. 2014, 24, 2193. (b) Burmistrov, V.; Morisseau, C.; Danilov, D.; Harris, T. R.; Dalinger, I.; Vatsadze, I.; Shkineva, T.; Butov, G. M.; Hammock, B. D. Bioorg. Med. Chem. Lett. 2015, 25, 5514. (c) Butov, G. M.; Burmistrov, V. V.; Danilov, D. V.; Pitushkin, D. A.; Morisseau, C.; Hammock, B. D. Russ. Chem. Bull. 2015, 64, 1569.

(11) Burmistrov, V. V.; Butov, G. M.; Pitushkin, D. A. Russ. J. Org. Chem. 2015, 51, 1795.

(12) Satchell, D. P. N.; Satchell, R. S. Chem. Soc. Rev. 1975, 2, 231.

(13) Habib, N. S.; Rieker, A. Synthesis 1984, 825.

(14) Turkevich, N. M.; Agaev, K. A.; Steblyuk, P. N.; Sementsiv, G. N. Khim.-Farm. Zh. 1982, 16, 1068.

(15) Sbei, N.; Haouas, B.; Chebbi, M.; Smida, Y. B.; Arfaoui, Y.; Boujlel, K.; Benkhoud, M. L. J. Sulfur Chem. 2017, 38, 152.

(16) Burmistrov, V. V.; Pitushkin, D. A.; Dyachenko, V. S.; Sdvijkov, D. V.; Kirilov, S. S.; Rasskazova, E. V.; Butov, G. M. Izvestia VSTU 2016, 4, 68 .

(17) General Experimental Procedure: To a solution of amine (5-10 $\mathrm{mmol}$ ) in $p$-xylene $(10-20 \mathrm{~mL}$ ) was added phenyl isothiocyanate ( 2 equiv) at room temperature. After heating to reflux for $3 \mathrm{~h}$, the reaction mixture was cooled to r.t. and conc $\mathrm{HCl}(1-2 \mathrm{~mL})$ was added. After stirring for $1 \mathrm{~h}$, the precipitate was filtered off, 
the filtrate was concentrated in vacuo and the residue was purified either by crystallization from $\mathrm{EtOH}$ (for solid compounds $\mathbf{5}$, $\mathbf{7}, \mathbf{8}, \mathbf{1 1}$ ) or by column chromatography (for liquid compounds 3 , 9, 10).

Analytical Data for Compound 3: Yield: $80 \%$; yellow oil; MS (EI): $m / z(\%)=221(5 \%)[\mathrm{M}]^{+}, 163(100 \%)[\mathrm{Ad}]^{+} ;{ }^{1} \mathrm{H}$ NMR $(500$ $\left.\mathrm{MHz}, \mathrm{CDCl}_{3}\right): \delta=2.17(\mathrm{~s}, 1 \mathrm{H}), 1.81(\mathrm{~s}, 2 \mathrm{H}), 1.62(\mathrm{dd}, J=13.0$, $12.0 \mathrm{~Hz}, 4 \mathrm{H}), 1.32$ (dd, J = 16.0, $12.5 \mathrm{~Hz}, 4 \mathrm{H}), 1.15$ (s, $2 \mathrm{H}), 0.87$ (s, $6 \mathrm{H}) .{ }^{13} \mathrm{C}$ NMR $\left(125 \mathrm{MHz}, \mathrm{CDCl}_{3}\right): \delta=129.92$ (s, $\left.1 \mathrm{C}, \mathrm{NCS}\right)$, 59.75 (s, 1 C, C-NCS), 49.88 (s, 1 C, Ad), 49.61 (s, 2 C, Ad), 42.26 (s, 1 C, Ad), 41.89 (s, 2 C, Ad), 32.58 (s, 1 C, Ad), 29.90 (s, 2 C, Ad), $29.62\left(\mathrm{~s}, 2 \mathrm{C}, 2 \mathrm{CH}_{3}\right)$. Elemental analysis calcd for $\mathrm{C}_{13} \mathrm{H}_{19} \mathrm{NS}$ : C, 70.54; H, 8.65; N, 6.33; S, 14.48; found: C, 70.59; H, 8.67; N, 6.29; S, 14.44 .

Analytical Data for Compound 9: Yield: 78\%; yellow oil; MS (EI): $m / z(\%)=221(15)[\mathrm{M}]^{+}, 135$ (100) $[\mathrm{Ad}]^{+} .{ }^{1} \mathrm{H}$ NMR $(500 \mathrm{MHz}$,
$\left.\mathrm{CDCl}_{3}\right): \delta=3.51\left(\mathrm{t}, J=7.5 \mathrm{~Hz}, 2 \mathrm{H}, \mathrm{CH}_{2}-\mathrm{NCS}\right), 1.96(\mathrm{~s}, 3 \mathrm{H}), 1.67$ (dd, $J=32.0,12.0 \mathrm{~Hz}, 4 \mathrm{H}), 1.54-1.49(\mathrm{~m}, 10 \mathrm{H}) .{ }^{13} \mathrm{C}$ NMR $(125$ $\mathrm{MHz}, \mathrm{CDCl}_{3}$ ): $\delta=128.99$ (s, $\left.1 \mathrm{C}, \mathrm{NCS}\right), 43.89$ (s, $1 \mathrm{C}, \mathrm{CH}_{2}-\mathrm{NCS}$ ), 41.88 (s, 3 C, Ad), 40.19 (s, 1 C, Ad-CH ) $^{2} 36.79$ (s, 3 C, Ad), 28.38 (s, 3 C, Ad), 27.54 (s, 1 C, quaternary $\mathrm{C}$ in Ad). Elemental analysis calcd for $\mathrm{C}_{13} \mathrm{H}_{19} \mathrm{NS}$ : C, 70.54; $\mathrm{H}, 8.65 ; \mathrm{N}, 6.33 ; \mathrm{S}, 14.48$; found: $\mathrm{C}$, 70.50; H, 8.66; N, 6.33; S, 14.45 .

Analytical Data for Compound 10: Yield: 86\%; brown oil; MS (EI): $m / z(\%)=221(12)[\mathrm{M}]^{+}, 163(8)\left[\mathrm{Ad}-\mathrm{CH}\left(\mathrm{CH}_{3}\right]^{+}, 135(100)\right.$ [Ad] ${ }^{+} .{ }^{1} \mathrm{H} \mathrm{NMR}\left(500 \mathrm{MHz}, \mathrm{CDCl}_{3}\right): \delta=3.35(\mathrm{q}, J=6.5 \mathrm{~Hz}, 1 \mathrm{H}, \mathrm{CH})$, $2.03(\mathrm{~s}, 3 \mathrm{H}), 1.74-1.46(\mathrm{~m}, 12 \mathrm{H}), 1.27\left(\mathrm{~d}, J=6.5 \mathrm{~Hz}, 3 \mathrm{H}, \mathrm{CH}_{3}\right)$. ${ }^{13} \mathrm{C}$ NMR (125 MHz, CDCl $\left.)_{3}\right): \delta=128.50$ (s, NCS), 63.68 (s, $1 \mathrm{C}$, $\mathrm{CH}$ ), 38.22 (s, 3 C, Ad), 36.90 (s, quaternary C in Ad), 36.72 (s, $3 \mathrm{C}, \mathrm{Ad}), 28.17$ (s, $3 \mathrm{C}, \mathrm{Ad}), 15.13$ (s, $1 \mathrm{C}, \mathrm{CH} 3$ ). Elemental analysis calcd for $\mathrm{C}_{13} \mathrm{H}_{19} \mathrm{NS}$ : $\mathrm{C}, 70.54 ; \mathrm{H}, 8.65 ; \mathrm{N}, 6.33 ; \mathrm{S}, 14.48$; found: $\mathrm{C}$, $70.51 ; \mathrm{H}, 8.66 ; \mathrm{N}, 6.32 ; \mathrm{S} 14.45$ 